\title{
Etiology of bacteremias associated with c-reactive protein, procalcitonin and lactate levels
}

\author{
MV de la Torre-Prados ${ }^{1,2^{*}}$, A García-de la Torre ${ }^{3}$, E Cámara-Sola ${ }^{1,2}$, A Puerto-Morlán 1,2, T Tsvetanova-Spasova ${ }^{1,2}$, \\ P Nuevo-Ortega ${ }^{1,2}$, C Rueda-Molina ${ }^{1,2}$, A Fernández-Porcel ${ }^{1,2}$, A García-Alcántara 1,2 \\ From ESICM LIVES 2015 \\ Berlin, Germany. 3-7 October 2015
}

\section{Introduction}

Because of the high morbidity and mortality associated with bacteremia, prompt evaluation and adequate therapy are of paramount importance. The clinical manifestations of gram- positive and gram-negative bacterial infections are similar while biomarkers may be useful for the early diagnosis of the nature of a pathogen.

\section{Objectives}

The purpose of the study was to evaluate the association between the level of C-Reactive Protein (CRP), procalcitonin (PCT), and lactate and the etiology of bacteremia.

\section{Methods}

We studied the role of these biomarkers with clustered gram-positive and gram-negative bacteremia in patients hospitalized in Intensive care Unit over a period of 2 years (2011-2013), they were measured within the 24 hours after the onset of severe sepsis or septic shock. The PCT was analyzed by immunoassay (Vidas, Brahms) ${ }^{\circledR}$, lactate and CRP was measured in DIMENSION RXL - SIEMENS ${ }^{\circledR}$ and blood culture was made in BACTEC- $9240^{\circledR}$ blood culture system (Becton Dickinson). The program used for the data processing and statistical analysis was SPSS $15.0^{\mathbb{B}}$.

\section{Results}

Our study included 396 patients, the median age of the study sample was 64 years old (inter-quartile range (IQR), $51-72), 60,6 \%$ were men, the main sources of infection were: respiratory tract (36\%) and intra-abdomen (26\%). In our series, APACHE II scores was 25 (IQR: 21-29.5), SOFA 10 (IQR: 7.75-11) and 24.8\% of 28-day mortality. Blood cultures were realized in 316 patients (79.9\%), 192 were

${ }^{1}$ Hospital Universitario Virgen de la Victoria, Department of Intensive Care Medicine, Málaga, Spain

Full list of author information is available at the end of the article negative and 7 cases the result were fungi, $58.62 \%$ had bacteremia due to gram-negative bacteria and $41.38 \%$ due to gram-positive, with 43 isolations Escherichia coli, were the most frequently isolated bacterium followed by Streptococcus pneumoniae (16.43\%) and Enterobacteria (14.29\%).

In the gram-negative bacteremia group, CRP levels plasma were higher 261 [IQR: 173.19-311.53] mg/dL vs. 200.2 [159.5-287.75] mg/dL than in the gram-positive bacteremia group, however PCT concentrations were statistically significant higher in the gram-negative bacteremia 27.04 [IQR: $13.47-84.23$ ] $\mathrm{ng} / \mathrm{mL}$ vs. 11.79 [2.61-22.67] ng/mL; $\mathrm{p}<0.001$; as well as lactate levels 3.1 [IQR: $1.97-4.7] \mathrm{mmol} / \mathrm{L}$ vs. 2.45 [1.64-4.22] $\mathrm{mmol} / \mathrm{L}$; $\mathrm{p}=0.04$.

\section{Conclusions}

PCT and lactate showed differences between gramnegative and gram-positive bacteremia, might be helpful in the differentiation of pathogenic bacteriemia and supposed the etiology before obtaining blood culture results.

\section{Authors' details}

${ }^{1}$ Hospital Universitario Virgen de la Victoria, Department of Intensive Care Medicine, Málaga, Spain. ${ }^{2}$ Instituto de Investigación Biomédica de Málaga (IBIMA), Málaga, Spain. ${ }^{3}$ Puerto Real University Hospital, Clinical Chemistry Department, Puerto Real, Spain.

Published: 1 October 2015

\section{Reference}

1. Brodská $\mathrm{H}$, et al: Significantly higher procalcitonin levels could differentiate Gram-negative sepsis from Gram-positive and fungal sepsis. Clin Exp Med 2013, 3:165-70.

doi:10.1186/2197-425X-3-S1-A788

Cite this article as: de la Torre-Prados et al:: Etiology of bacteremias associated with c-reactive protein, procalcitonin and lactate levels. Intensive Care Medicine Experimental 2015 3(Suppl 1):A788.

\section{SpringerOpen ${ }^{\circ}$}

(c) 2015 de la Torre-Prados et al.; This is an Open Access article distributed under the terms of the Creative Commons Attribution License (http://creativecommons.org/licenses/by/4.0), which permits unrestricted use, distribution, and reproduction in any medium, provided the original work is properly cited. 